\title{
Estresse salino na germinação e formação de porta-enxerto de aceroleira ${ }^{1}$
}

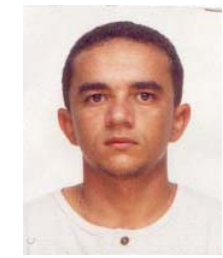

Marcelo T. Gurgel ${ }^{2}$, Pedro D. Fernandes ${ }^{3}$, Francisco J. de S. Santos ${ }^{4}$, Hans R. Gheyi ${ }^{3}$, Idelfonso L. Bezerra ${ }^{5}$ \& Reginaldo G. Nobre ${ }^{5}$

\author{
1 Parte da Dissertação de Mestrado do primeiro autor apresentada à UFPB - Campina Grande, PB \\ 2 UFCG/CCT/DEAg. Rua Aprígio Veloso 882, Bodocongó, CEP 58109-970, Campina Grande, PB. Fone: (83) 310-1285. \\ E-mail: mtgurgel@bol.com.br (Foto) \\ ${ }^{3}$ UFCG/CCT/DEAg. Campina Grande, PB. Fone: (83) 310-1285, Fax: (83) 310-1307 \\ ${ }^{4}$ EMBRAPA Agroindústria. Rua Dra. Sara Mesquita 2270, Pici, CP 3761, CEP 60511-110, Fortaleza, CE. \\ ${ }^{5}$ Mestrando, UFCG/CCT/DEAg. CEP 58109-970, Campina Grande, PB
}

Protocolo 8 - 22/1/2002 - Aprovado em 11/2/2003

\begin{abstract}
Resumo: A utilização de águas com problemas de salinidade é uma das principais causas do insucesso na produção de mudas de espécies frutíferas, principalmente daquelas sem qualquer estudo prévio de tolerância ao estresse salino, como é o caso da aceroleira. Considerando a importância dessa espécie, entre as fruteiras irrigadas no Nordeste brasileiro, realizou-se o presente trabalho, com o objetivo de se avaliar os efeitos da salinidade da água de irrigação (CEa), variando entre 0,5 e 5,5 dS m m $^{-1}$, sobre a fase de germinação e formação do porta-enxerto de aceroleira clone BV1. As águas foram preparadas mantendo-se a proporção de 7:2:1, entre $\mathrm{Na:Ca:Mg.} \mathrm{As} \mathrm{variáveis}$ foram afetadas pela salinidade, tanto na germinação quanto na fase de formação do porta-enxerto. A percentagem de plantas emergidas foi menos prejudicada que o índice de velocidade de emergência; diminuiu a sensibilidade das mudas ao estresse salino ao longo do tempo, possibilitando-se classificar o clone BV1 de aceroleira como 'moderadamente sensível' à salinidade, na época da enxertia.
\end{abstract}

Palavras-chave: Malpighia emaginata D.C, condutividade elétrica, estresse salino

\section{Germination and rootstock development of West Indian cherry under saline stress}

\begin{abstract}
The use of water of marginal quality is one of the main causes of failure of production of seedlings and the especially of those crops without any previous study of salinity tolerance, as is the case of West Indian cherry. Considering the importance of this specie among irrigated fruits in northeast Brazil, the present study was conducted with the objective to evaluate the effects of 6 level of electrical conductivity of irrigation water (ECw) varying from 0.5 to $5.5 \mathrm{dS} \mathrm{m}^{-1}$ on germination and formation of rootstocks of West Indian cherry (clone BV1). The irrigation water of

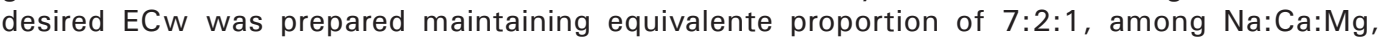
respectively. All the variables studied were affected by salinity during germination and phase of rootstock formation. The percentage of plants emerged was found to be affected less than the emergency speed and seedlings showed less susceptibility to salinity with time. The clone BV1 of West Indian cherry may be classified as 'moderately sensitive' during the grafting phase.
\end{abstract}

Key words: Malpighia emaginata D.C, eletrical condutivity, saline stress

\section{INTRODUÇÃO}

Com área superior a dois milhões de hectares cultivados com fruteiras, o Brasil já foi o maior produtor mundial de frutas, estando hoje em segundo lugar. Apesar de produzir mais de 30 milhões de toneladas de frutas e faturar, anualmente, 60 milhões de dólares com exportações, o pais está classificado em $90^{\circ}$ lugar como exportador mundial (Bandeira et al., 1998).

Dentre os principais cultivos frutícolas destaca-se o de acerola, com perspectivas promissoras, em virtude das condições climáticas favoráveis à sua exploração, em quase todo o território nacional (Alves, 1989). Em vista do altíssimo teor de vitamina $\mathrm{C}$ e de sua importância na medicina mundial, a acerola é, atualmente, em termos relativos, uma das primeiras culturas de exportação da fruticultura brasileira. Esta frutífera está sendo consumida cada vez mais por japoneses, europeus e norte-americanos (Lucas, 1993).

A fruticultura irrigada é uma das atividades agrícolas com maior crescimento no Nordeste, desde as últimas décadas, a ponto de se constituir num dos principais vetores para o desenvolvimento econômico de áreas semi-áridas. Entretanto, o não conhecimento do teor médio de sais na zona radicular 
que as fruteiras podem tolerar, tem restringido a utilização e/ou favorecido o mau uso dos recursos hídricos existentes no Nordeste.

Sabe-se, também, que as espécies e cultivares se comportam diferentemente em relação à salinidade, isto é, cada espécie de planta ou cultivar tolera até certo nível de salinidade, sem reduzir o seu rendimento potencial (salinidade limiar - SL). A partir desse limite, passa a diminuir a produtividade com o incremento da salinidade do solo ou da água (Maas \& Hoffman, 1977; Rhoades \& Loveday, 1990; Medeiros, 1998). Desta forma, a identificação da condutividade elétrica da solução do solo, crítica para a cultura explorada, é fundamental para melhorar o manejo das áreas irrigadas. Além disso, é interessante se identificar espécie vegetais tolerantes a altos níveis de salinidade de água, como determinados tipos de fruteiras (Ayers \& Westcot, 1991).

A qualidade da água de irrigação é fator importante na salinização dos solos de regiões áridas e semi-áridas, com conseqüências sobre a degradação física do solo e o desenvolvimento das culturas (Ayers \& Westcot, 1991).

Sobre a aceroleira, inexistem trabalhos com qualidade de água, fazendo-se necessários estudos sobre níveis de salinidade de água toleráveis na fase inicial de cultivo; constituirão contribuições importantes para a solução de problemas dos produtores de mudas de aceroleira.

Ante a falta de resultados de pesquisas envolvendo salinidade na cultura da acerola, este trabalho teve por objetivo estudar os efeitos do uso de águas salinas sobre a germinação e a formação de porta-enxerto dessa espécie.

\section{MATERIAL E MÉTODOS}

O ensaio foi conduzido em viveiro no Campo Experimental de Pacajus (CEP), pertencente à EMBRAPA Tropical Agroindústria, no Estado do Ceará, no período de fevereiro a maio de 2001.

Avaliaram-se os efeitos de seis níveis de condutividade elétrica da água de irrigação (CEa: 0,5, 1,5, 2,5, 3,5, 4,5 e 5,5 dS $\mathrm{m}^{-1}$ ) caracterizados de $\mathrm{S}_{1}$ a $\mathrm{S}_{6}$, respectivamente, sobre a germinação e a formação do porta-enxerto de aceroleira clone BV1, até a fase de enxertia, no delineamento em blocos casualizados, com quatro repetições e 54 plantas por parcela.

O substrato foi uma mistura de casca de arroz carbonizada, palha de carnaúba triturada e húmus, na proporção $2: 1: 1$ (Chaves et al., 2000). As características químicas quanto à salinidade (Richards, 1954) e à fertilidade (EMBRAPA, 1997) estão indicadas na Tabela 1 .

Utilizaram-se, como recipientes para o substrato, tubetes plásticos de $19 \mathrm{~cm}$ de altura e $6,3 \mathrm{~cm}$ de diâmetro, com capacidade de $288 \mathrm{~cm}^{3}$, abertos na parte inferior para permitir a livre drenagem e dispostos em bandejas, apoiadas a $0,8 \mathrm{~m}$ de altura no solo.

Na preparação das águas de irrigação, adotou-se a relação entre a CEa e concentração salina $\left(\mathrm{mmol}_{\mathrm{c}} \mathrm{L}^{-1}=\mathrm{CEa} 10\right)$, extraída de Rhoades et al. (1992) e válida para até $5 \mathrm{dS} \mathrm{m}^{-1}$. As águas foram preparadas a partir de solução $1 \mathrm{~N} \mathrm{de} \mathrm{NaCl}, \mathrm{CaCl}_{2} 2 \mathrm{H}_{2} \mathrm{O}$ e $\mathrm{MgCl}_{2} 6 \mathrm{H}_{2} \mathrm{O}$, utilizando-se de água de poço cristalino do sistema
Tabela 1. Características químicas do substrato utilizado no experimento

\begin{tabular}{|c|c|}
\hline Características Químicas & Valor \\
\hline \multicolumn{2}{|l|}{ Complexo Sortivo $\mathrm{mmol}_{\mathrm{c}} \mathrm{dm}^{-3}$} \\
\hline Cálcio & 88,86 \\
\hline Magnésio & 40,80 \\
\hline Sódio & 130,00 \\
\hline Potássio & 34,00 \\
\hline Hidrogênio + Alumínio Ac. Potencial & 26,00 \\
\hline Soma de bases $(\mathrm{S})$ & 293,66 \\
\hline Capacidade de troca de cátions (CTC) & 319,66 \\
\hline Saturação de bases (V), \% & 91,87 \\
\hline Percentagem de sódio trocável, PST (\%) & 40,67 \\
\hline Matéria orgânica, $\left(\mathrm{g} \mathrm{dm}^{-1}\right)$ & 215,40 \\
\hline Fósforo (resina), $\mathrm{mg} \mathrm{dm}^{-3}$ & 48,87 \\
\hline Manganês, $\mathrm{mg} \mathrm{dm}^{-3}$ & 5,40 \\
\hline Zinco, $\mathrm{mg} \mathrm{dm}^{-3}$ & 293,66 \\
\hline Cobre, $\mathrm{mg} \mathrm{dm}^{-3}$ & 4,41 \\
\hline Ferro, $\mathrm{mg} \mathrm{dm}^{-3}$ & 19,20 \\
\hline Condutividade elétrica do extrato de saturação, $\mathrm{dS} \mathrm{m}^{-1}$ & 5,30 \\
\hline
\end{tabular}

de irrigação do Campo Experimental de Pacajus - CEP. A quantidade de cada componente empregado no preparo das águas de irrigação $\left(\mathrm{NaCl}, \mathrm{CaCl}_{2} \cdot 2 \mathrm{H}_{2} \mathrm{O}, \mathrm{MgCl}_{2} \cdot 6 \mathrm{H}_{2} \mathrm{O}\right.$ e água de poço do sistema de irrigação) foi determinada de forma a se obter a CEa de cada tratamento, considerando-se a proporção equivalente 7:2:1 para $\mathrm{Na}: \mathrm{Ca}: \mathrm{Mg}$, respectivamente. A proporcionalidade utilizada para $\mathrm{Na}: \mathrm{Ca}: \mathrm{Mg}$ é, de acordo com Medeiros (1992), uma aproximação representativa da maioria das fontes de água disponível para irrigação no Nordeste brasileiro.

Após o enchimento dos tubetes, foram feitas oito lavagens com $2 \mathrm{~L}$ da água do poço $\left(0,5 \mathrm{dS} \mathrm{m}^{-1}\right)$, em cada aplicação, visando a se reduzir a condutividade elétrica do substrato; no dia anterior à semeadura, cada bandeja (parcela) foi irrigada com $2 \mathrm{~L}$ da água salina correspondente a cada tratamento. $\mathrm{O}$ semeio constou de cinco sementes por tubete, em virtude do não desenvolvimento do embrião em muitas sementes de aceroleira, algumas vezes em proporção superior a 50 \% (Musser et al., 1991).

As irrigações foram diárias, com regadores, em uma única aplicação ao final do turno vespertino, utilizando-se de águas com condutividade elétrica correspondente aos tratamentos $\left(0,5,1,5,2,5,3,5,4,5\right.$ e 5,5 dS m ${ }^{-1}$ a $\left.25^{\circ} \mathrm{C}\right)$. O volume aplicado foi de forma a se obter uma drenagem em torno de $40 \%$, visando favorecer o crescimento e o desenvolvimento das mudas e lavar o excesso de sais do substrato. Em cada tubete deixou-se apenas uma plântula, a primeira que emergia com aspecto normal; quando não houve germinação em um tubete, procedeu-se à repicagem de uma plântula dentro da própria parcela.

Foram feitas adubações via foliar, quinzenalmente, após o surgimento das primeiras folhas verdadeiras, com Ubifol ${ }^{1}+$ Nitrocálcio ${ }^{2}$ na proporção de $1 \mathrm{~mL}$ do adubo para $1 \mathrm{~L}$ d'água, aplicando-se $400 \mathrm{~mL}$ por parcela.

Na germinação, foi analisada a percentagem de plântulas emergidas (PPE), aos 40 dias após o semeio (DAS), usando-se,

${ }^{\prime} \mathrm{N}(15 \%), \mathrm{P}_{2} \mathrm{O}_{5}(15 \%), \mathrm{K}_{2} \mathrm{O}(20 \%), \mathrm{Ca}(1,5 \%), \mathrm{Mg}(0,05 \%), \mathrm{Zn}(0,20 \%), \mathrm{B}(0,05 \%), \mathrm{Fe}(0,10 \%)$, Mn $(0,02 \%)$, Cu $(0,05 \%)$, Mo $(0,01 \%)$ e S $(3 \%)$.

${ }^{2} \mathrm{~N}(22 \%)$ e Ca $(7 \%)$ 
como critério, a emergência do epicótilo na superfície do tubete (Brasil, 1992), foi avaliado, também, o índice de velocidade de emergência (IVE), calculado com base em Vieira \& Carvalho (1994):

$$
\operatorname{IVE}=\frac{\mathrm{e}_{1}}{\mathrm{~N}_{1}}+\frac{\mathrm{e}_{2}}{\mathrm{~N}_{2}}+\ldots+\frac{\mathrm{e}_{\mathrm{n}}}{\mathrm{N}_{\mathrm{n}}}
$$

em que:

$$
\begin{aligned}
& \mathrm{e}_{1}, \mathrm{e}_{2}, \ldots \mathrm{e}_{\mathrm{n}} \text { - número de plântulas emergidas, na primeira, } \\
& \text { segunda, ... última contagem } \\
& \mathrm{N}_{1}, \mathrm{~N}_{2}, \ldots \mathrm{N}_{\mathrm{n}} \text { - número de dias a partir da semeadura na } \\
& \text { primeira, segunda, ..., última contagem }
\end{aligned}
$$

As plantas do porta-enxerto foram avaliadas aos 50 e 90 dias após a emergência da primeira plântula (DAE), através de número de folhas (NF), altura de plantas (AP), diâmetro do caule (DC), fitomassa seca da parte aérea (FSA) e fitomassa seca da raiz (FSR). Aos 90 DAE, avaliou-se ainda a percentagem de plantas aptas à enxertia (PAE), considerando-se o número total de plantas existentes na parcela (NTP) e o número das que estavam aptas à enxertia (NAE):

$$
\mathrm{PAE}=\frac{\mathrm{NAE}}{\mathrm{NTP}} 100
$$

Os resultados foram submetidos à avaliação pelo teste "F" e análise polinomial (Ferreira, 2000).

\section{RESULTADOS E DISCUSSÃO}

\section{Germinação}

A salinidade reduziu linearmente o processo germinativo avaliado aos 40 DAS (Figura 1), expresso pela percen-tagem de plântulas emergidas (PPE) $(\mathrm{p}<0,05)$ e pelo índice de velocidade de emergência (IVE) $(p<0,01)$. Foram observados aos 40 DAS decrementos lineares. Os decrementos para PPE e IVE foram, respectivamente, de 6,23 e 9,04\%, por aumento unitário da $\mathrm{CEa}$ (quando comparado com $\mathrm{S}_{1}-0,5 \mathrm{dS} \mathrm{m}^{-1}$ ). Observa-se que o IVE foi mais afetado pela CEa, quando comparado com a PPE; sabe-se que a salinidade, ao reduzir o potencial osmótico do meio, aumenta o tempo de embebição de água pelas sementes, resultando, inicialmente, em prolongamento do período de emergência da plântula (Pizarro, 1985); uma menor absorção de água pelas sementes afeta a percentagem de germinação (Menguel \& Kirkby, 1987; Rhoades \& Loveday, 1990).

Vários autores têm constatado redução da velocidade de emergência em outras espécies, devido à diminuição do potencial osmótico, quer através de tratamentos de salinidade, como no caso de melão, estudado por Oliveira et al. (1998), quer mediante simulação de estresse, induzido por agentes osmóticos, como nos casos de Magalhães \& Carrelli
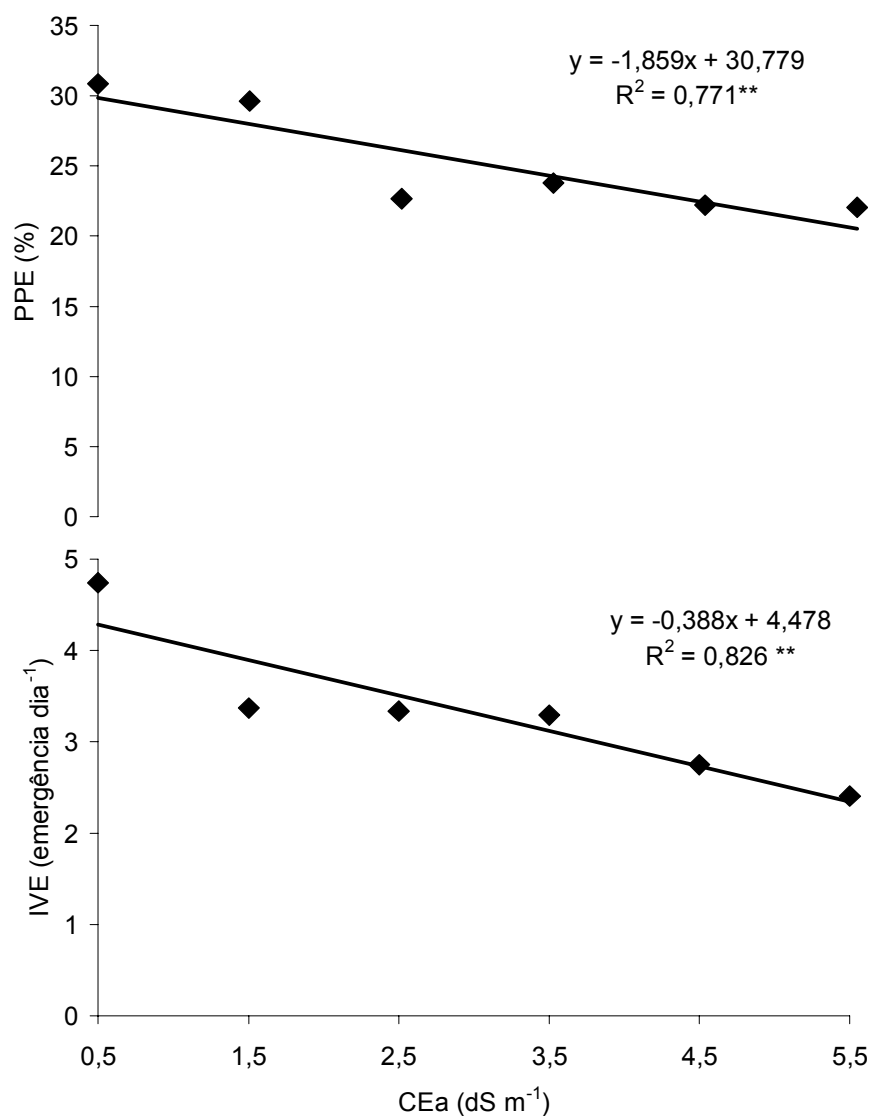

Figura 1. Percentagem de plantas emergidas (PPE) e índice de velocidade de emergência (IVE) da aceroleira aos 40 dias após a semeadura (DAS) em função da salinidade da água de irrigação

(1972) em feijão, Sharma (1976) em forrageiras, e Pereira (1997) em algodão.

\section{Formação de mudas}

O crescimento das plantas, com base no número de folhas (Figura 2A), sofreu declínio linear de $11,66 \%$ por aumento unitário da $\mathrm{CEa}$ aos $50 \mathrm{DAE}$, em relação às plantas irrigadas com água de $0,5 \mathrm{dS} \mathrm{m}^{-1}$. Aos $90 \mathrm{DAE}$, os dados se ajustaram mais adequadamente ao modelo quadrático, com incremento de NF até CEa de 3,96 $\mathrm{dS} \mathrm{m}^{-1}$; a partir desse nível, constataramse reduções de 9,07 e 32,20\%, respectivamente, para as águas de 4,5 e 5,5 $\mathrm{dS} \mathrm{m}^{-1}$. Percebe-se, pelo número de folhas, um aumento da tolerância da aceroleira à salinidade da água entre 50 e 90 DAE.

Segundo a literatura, em condições de deficiência hídrica induzida pelo efeito osmótico (seca fisiológica) é comum ocorrerem alterações morfológicas e anatômicas nas plantas, como medida de manter a absorção de água e reduzir a taxa de transpiração; dentre as mudanças morfológicas destacam-se a redução do tamanho e do número de folhas (Maas \& Nieman, 1978; Shannon, 1979; Fageria, 1984; Fageria, 1989). Trabalhando com sementes de clones de cajueiro anão precoce, em substratos de diferentes níveis de salinidade, Soares (1998) observou redução significativa no número de folhas (cerca de $20 \%$ ) com o aumento da salinidade da água de 0,45 para $6,50 \mathrm{dS} \mathrm{m}^{-1}$. 

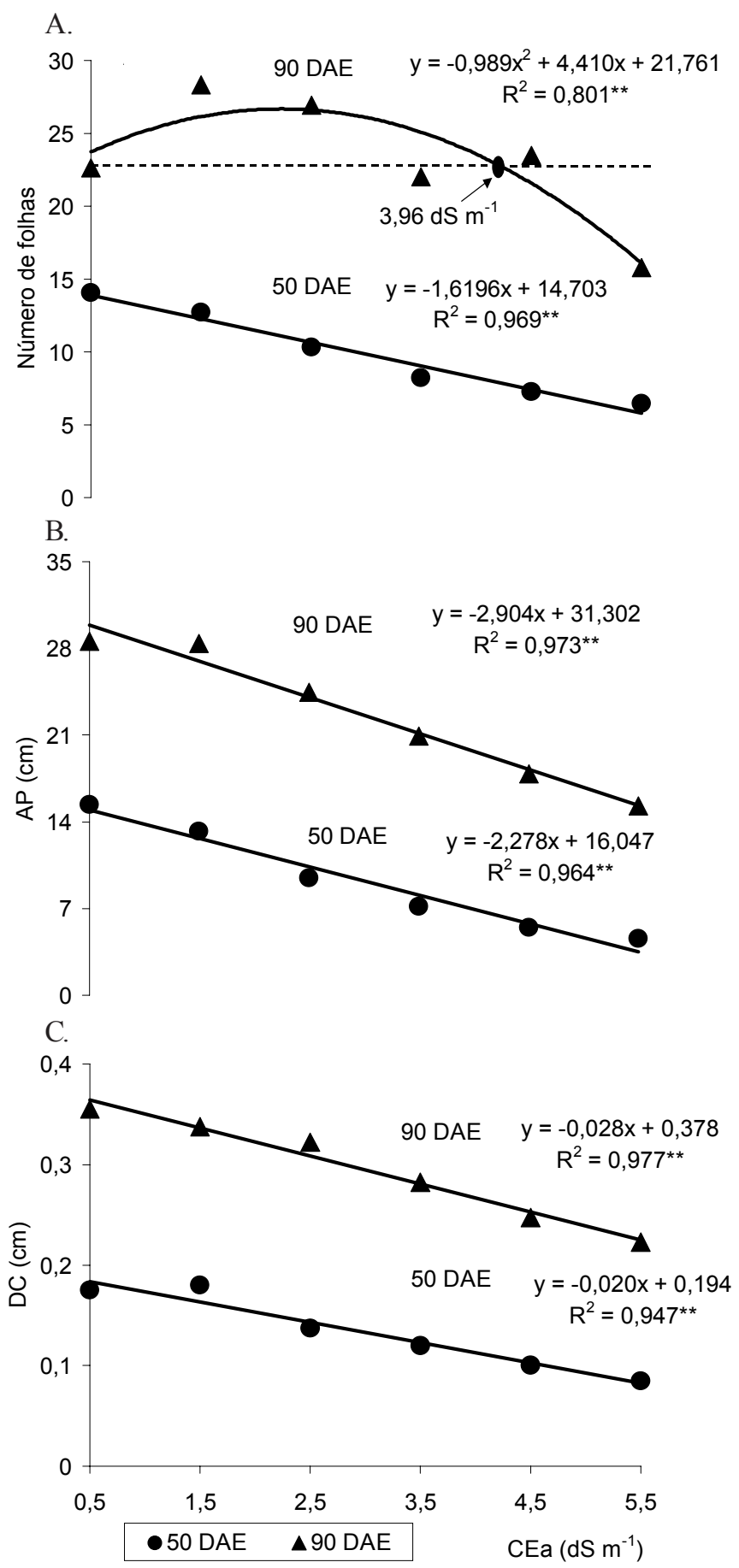

Figura 2. Número de folha (NF), altura de planta (AP) e diâmetro do caule (DC) da aceroleira, aos 50 e 90 dias após a emergência da primeira plântula (DAE), em função da salinidade da água de irrigação

Quanto à altura de plantas constata-se, pelos estudos de regressão (Figura 2B), ter havido efeito negativo dos tratamentos salinos de forma linear $(p<0,01)$ aos 50 e 90 DAE, com decrementos de 15,28 e 9,73\%, respectivamente, por aumento unitário da $\mathrm{CEa}$, em relação a $\mathrm{S}_{1}$. Portanto, semelhante ao ocorrido com o número de folhas, a influência negativa da salinidade sobre a altura de planta diminuiu com o tempo de cultivo, uma vez que esta variável foi mais sensível aos 50 DAE (decréscimo de 76,40\% em $\mathrm{S}_{6}$ ) que aos 90 DAE (decréscimo de 48,65\% em $\mathrm{S}_{6}$ ); isso confirma observações de Menguel \& Kirkby (1987), que as plantas nas diferentes fases de crescimento, não se comportam de mesma forma quando submetidas às condições de salinidade.

Quanto ao desenvolvimento das plantas, verificou-se redução linear de 11,01 e 7,64\% no diâmetro do caule (Figura 2C), por incremento unitário da salinidade aos 50 e 90 DAE, respectivamente. Similarmente ao número de folhas e altura de plantas, a maior influência negativa da salinidade sobre o diâmetro do caule ocorreu aos 50 DAE, evidenciando maior sensibilidade da aceroleira à salinidade na fase inicial de crescimento. Os resultados são diferentes dos observados em cajueiro-anão precoce por Soares (1998), ao registrar, com o tempo, efeito mais negativo da salinidade sobre o diâmetro do caule de alguns clones.

\section{Fitomassa seca da parte aérea e da raiz}

A salinidade da água de irrigação afetou negativamente a produção de fitomassa seca da parte aérea (FSA) com ajustamento quadrático aos $50(\mathrm{p}<0,01)$ e linear $(\mathrm{p}<0,01)$ aos 90 DAE (Figura 3 ). Os decrementos obtidos aos 50 DAE foram de 26,91, 48,09, 63,53, 73,23 e 77,19\%, para as águas de 1,5,2,5, $3,5,4,5$ e 5,5 dS m$~^{-1}$, enquanto aos 90 DAE o decréscimo foi de $13,15 \%$ por aumento unitário da $\mathrm{CEa}$, em relação à água de $0,5 \mathrm{dS} \mathrm{m}^{-1} ;$ em $\mathrm{S}_{6}$ a redução foi de $65,75 \%$, inferior à diminuição proporcionada pela água $\mathrm{S}_{6}$, aos $50 \mathrm{DAE}$.

Com base nos decréscimos de fitomassa, verifica-se ter aumentado com o tempo a tolerância do clone BV1 de aceroleira, com o incremento da salinidade da água de irrigação. Segundo Lima (1997), isto ocorre com a maioria das culturas, embora existam exceções, como o arroz, que é mais afetado durante o florescimento. Vários autores têm reportado que a tolerância das espécies varia durante o ciclo fenológico (Shainberg \& Oster, 1978; Bresler et al., 1982; Fageria, 1989).

A fitomassa seca da raiz (FSR) foi, também, afetada negativamente pela salinidade da água de irrigação, em ambas as datas de avaliação $(\mathrm{p}<0,01)$, sendo o efeito linear e quadrático aos 50 e 90 DAE, respectivamente (Figura 3). A perda relativa aos 50 DAE foi de $17,96 \%$, por aumento unitário da CEa, quando comparada com os valores das plantas irrigadas com água de $0,5 \mathrm{dS} \mathrm{m}^{-1}$. Os decréscimos relativos aos $90 \mathrm{DAE}$ foram de $30,97,54,42,70,34,78,72$ e 79,57\%, para as águas de 1,5, 2,5, 3,5, 4,5 e 5,5 $\mathrm{dS} \mathrm{m}^{-1}$, respectivamente Comparando-se os decréscimos de FSR no mais alto nível de salinidade da água $\left(5,5 \mathrm{dS} \mathrm{m}^{-1}\right)$, aos 50 e $90 \mathrm{DAE}(89,80$ e 79,57\%), com os obtidos para FSA $(77,19$ e $65,75 \%)$, constata-se maior dano da salinidade sobre o sistema radicular nas respectivas idades das plantas. $\mathrm{O}$ fato pode ser uma característica da espécie em estudo, que por ter sementes com poucas reservas, utilizam-nas, inicialmente, no crescimento da parte aérea para garantir melhores condições de fotossíntese passando, em seguida, a incrementar a massa radicular, visando acelerar a absorção de água devido ao baixo potencial osmótico, uma vez que as raízes foram menos afetadas aos 90 DAE que aos 50 DAE.

Desta forma, o uso do sistema radicular é mais apropriado para se avaliar os efeitos da salinidade durante o crescimento inicial da aceroleira, quando comparado com a parte aérea. 

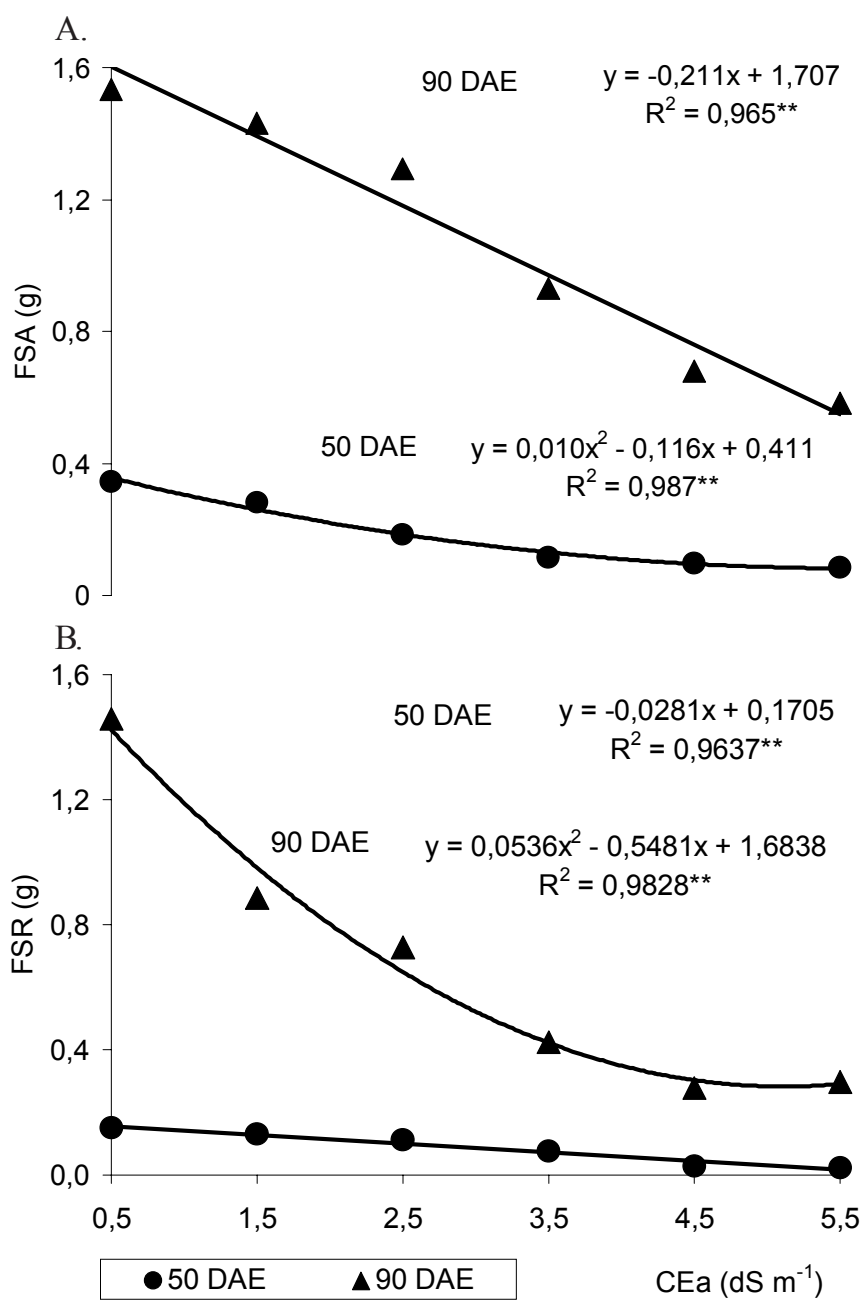

Figura 3. Fitomassa seca da parte aérea (FSA) e de raiz (FSR) da aceroleira, aos 50 e 90 dias após a emergência da primeira plântula (DAE), em função da salinidade da água de irrigação

\section{Plantas aptas à enxertia}

Pelo estudo de regressão segmentada (modelo platô) aplicada aos dados de percentagem de plantas aptas à enxertia (PAE), aos 90 DAE (Figura 4), verifica-se que o limite de CEa a partir do qual ocorreu decréscimo desta variável foi de 1,16 $\mathrm{dS} \mathrm{m}{ }^{-1}$, seguido de taxa de decréscimo relativo de $15,03 \%$ por

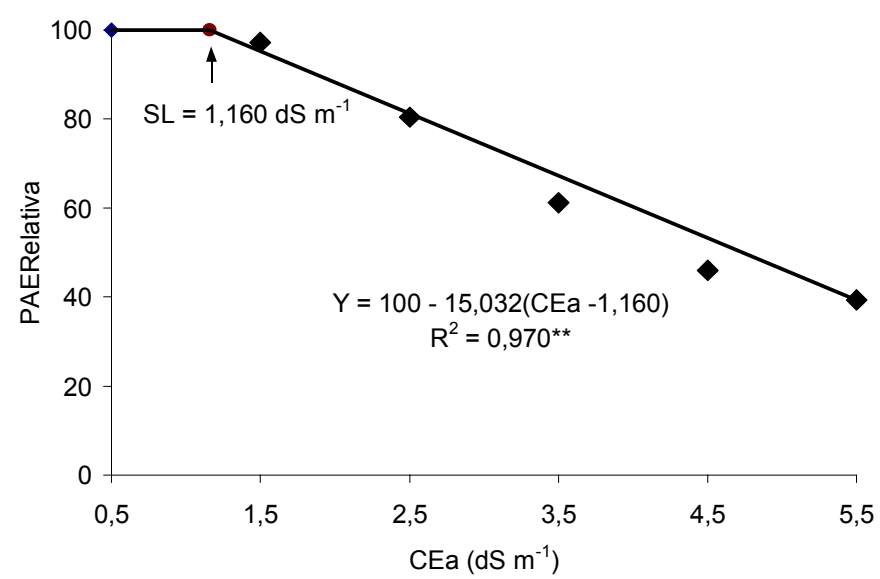

Figura 4. Percentagem de plantas aptas à enxertia (PAE) aos 90 dias após a emergência da primeira plântula (DAE) em função da salinidade da água de irrigação aumento unitário da CEa. Segundo critérios contidos em Ayers \& Westcot (1991), na fase de formação de porta-enxerto a aceroleira seria classificada como 'moderadamente sensível'.

Os dados de PAE, em função dos níveis de salinidade, reforçam o efeito negativo da salinidade, ao longo do tempo, sobre as variáveis altura da planta e diâmetro do caule, que segundo Chaves et al. (2000), devem ser levadas em consideração no momento de se efetuar a enxertia.

Meireles (1999) também verificou redução significativa no número de plantas aptas à enxertia de clones de cajueiro anãoprecoce, quando submetidos a diferentes níveis de salinidade da água de irrigação (variando entre 0,26 e 2,63 dS m-1).

\section{CONCLUSÕES}

1. O estresse salino prejudica de forma linear a percentagem de plantas emergidas e a velocidade de emergência.

2. Na fase de formação de mudas, com o passar do tempo aumenta a tolerância do clone BV1 à salinidade.

3. Durante a formação do porta-enxerto, o efeito da salinidade é mais intenso sobre o sistema radicular que sobre a parte aérea.

4. O clone BV1 de aceroleira tolera até $1,16 \mathrm{dS} \mathrm{m} \mathrm{m}^{-1}$ de condutividade elétrica da água de irrigação $(\mathrm{CEa})$, sem haver prejuízos sobre a enxertia, podendo ser classificada como 'moderadamente sensível' nesta fase.

\section{LITERATURA CITADA}

Alves, R.E. Contribuição do estudo da acerola (Malpighia glabra L.): propagação assexuada e teores de nutrientes. Areia: UFPB,1989, 79p. Monografia Graduação

Ayers, R.S.; Westcot, D.W. A qualidade da água na agricultura. Campina Grande: UFPB, 1991. 218p. FAO. Estudos de Irrigação e Drenagem, 29

Bandeira, C.T.; Miranda, F.R. de; Sobrinho, R.B.; Cardoso, J.E. Produção de dois clones de acerola (Malpighia glabra L.) sob diferentes regimes de irrigação. Fortaleza: EMBRAPA, Pesquisa em andamento, n.18. ago. 1998, 5p.

Brasil. Ministério da Agricultura e Reforma Agrária. Regras para análise de sementes. Brasília: DNDV, CLAV, 1992. 365p.

Bresler, E.; Mcneal, B.L.; Carter, D.L. Saline and sodic soil: Principles, dynamics and modeling. Berlin: Springer-Verlag, 1982. 249p.

Chaves, J.C.M.; Cavalcante Jr., A.T.; Correia, D.; Souza, F.X. de; Araújo, C.A.T. Normas de produção de mudas. Fortaleza: Embrapa Agroindústria Tropical, 2000. 37p. Documento, 41

EMBRAPA. Manual de métodos de analise de solo. Centro Nacional de Pesquisa de Solos. $2^{\text {a }}$ ed. Rev. atual. Rio de Janeiro, 1997. 212p. EMBRAPA-CNPS. Documento, 1

Fageria, N.K. Adubação e nutrição mineral da cultura de arroz. Rio de Janeiro: Campus; Goiânia: EMBRAPA, 1984. cap.10, p.302-2.

Fageria, N.K. Solos tropicais e aspectos fisiológicos das culturas. Brasília: EMBRAPA, DPU, 1989. 425p .EMBRAPACNPAF. Documento, 18 
Ferreira, P.V. Estatística experimental aplicada à agronomia. Maceió: UFAL, EDUFAL, FUNDEPES, 2000. 437p.

Lima, L.A. Efeito de sais no solo e na planta. In: Gheyi, H.R.; Queiroz, J.E. Medeiros, J.M. (ed). Manejo e controle da salinidade na agricultura. Campina Grande: UFPB, SBEA, 1997.p.113-136.

Lucas, A.P. Acerola: suco da saúde conquista o mundo inteiro. Manchete Rural, Rio de Janeiro, v.5, n.69, 1993. p.10-13.

Maas, E.V.; Hoffman, G. J Crop salt tolerance - Current assessment. Jounal of Irrigation and Drainage of ASCE, New York, v.103.p.115-134. 1977.

Maas, E.V.; Nieman, R.H. Physiology of plant tolerant to salinity. In: Jung, G.A. (ed.). Crop tolerance to sub-optimal land conditions. Madison: American Society. Agronomy 1978. cap. 1.p.277-9. Special Publication, 32

Magalhães, A.C.N.; Carelli, M.L. Germinação de sementes de feijão (Phaseolus vulgaris L.) sob condições variadas de pressão osmótica. Bragantia, Campinas, v.31, n.5, p.19-26, 1972.

Medeiros, J.F. de. Qualidade da água de irrigação e evolução da salinidade nas propriedades assistidas pelo "GAT" nos Estados do RN, PB e CE. Campina Grande: UFPB, 1992. 173p. Dissertação Mestrado

Medeiros, J.F. de. Manejo da água de irrigação salina em estufa cultivada com pimentão. Piracicaba: ESALQ, 1998. 152p. Tese Doutorado

Meireles, A.C.M. Salinidade da água de irrigação e desenvolvimento de mudas de cajueiro anão-precoce (Anacardium occidentale L.). Fortaleza: UFC, 1999. 60p. Dissertação Mestrado

Menguel, K.; Kirkby, E.A. Principles of plant nutrition. 4 ed. Bern: International Potash Institute, 1987. 687p.

Musser, R.S.; Couceiro, E. M.; Albuquerque, M. H. Efeito do ácido naftalenoacético no enraizamento de estacas semilenhosas da aceroleira em sistema de microaspersão. In: Congresso Brasileiro de Fruticultura, 9, 1989, Fortaleza. Anais... Fortaleza: SBF, BNS, 1991, p.79-83.
Oliveira, P.M.; Blank, F.A.; Pereira, A.J.; Lima, L.A. Efeitos da salinidade da água sobre a germinação de melão. Revista Brasileira de Engenharia Agrícola e Ambiental, v.2, n.2, p.235-238. 1998.

Pereira, J.R. Genótipos de algodoeiro herbáceo (Gossypium hirsutum L. R. Latifolium H.) submetidos a estresse hídrico na fase de germinação. Campina Grande: UFPB, 1997. 136p. Dissertação Mestrado

Pizarro, F. Drenaje agrícola y recuperacion de suelos salinos. Madrid. Editora Agrícola Española, S.A., 1985. 542p.

Rhoades, J.D.; Kandiah, A; Mashali, A.M. The use of saline waters for crop production. Rome: FAO, 1992. 133p. FAO. Irrigation and Drainage Paper, 48

Rhoades, J.D.; Loveday, J.G. Salinity in irrigated agriculture. In: Stewart, D.R.; Nielsen, D.R. (eds.) Irrigaton of agricultural crops. Madison: ASA, CSSA, SSSA, 1990. p.1089-1142. Agronomy, 30

Richards, L.A. (ed.) Diagnosis and improvement of saline and alkali soils. Washington: United States Salinity Laboratory, 1954. 160p. USDA. Agriculture Handbook, 60

Shainberg, I; Oster, J.D. Quality of irrigation water. Bet Dagan: International Irrigation Center, 1978. 65p.

Shannon, M.C. In quest of rapid screening techniques for plant salt tolerance. Horticulture Science, Fort Collins, v.14, n.5, p.587-589, 1979 .

Sharma, M.L. Interaction of water potential and temperature effects on germination of three semi-arid plant species. Agronomy Journal, Madison, v.68, p.390-394, 1976.

Soares, A.C.D. Tolerância de porta-enxertos e enxertos de cajueiro anão-precoce (Anacardium occidentale L.) à salinidade do substrato. Fortaleza: UFC, 1998. 40p. Dissertação Mestrado

Vieira, R.D; Carvalho, N.M. Teste de vigor em sementes. Jaboticabal: FUNEP, UNESP-FCAVJ, 1994. 164p. 